\title{
Evaluación de actividades enzimáticas de Fusarium spp., aislados de lesiones en humanos, animales y plantas
}

\author{
María Fernanda Valencia-Guerrero', Balkys Quevedo-Hidalgo', Marcela Franco-Corrrea ${ }^{2}$, \\ Hugo Díez-Ortega ${ }^{3}$, Claudia Marcela Parra-Giraldo ${ }^{2}$, María Ximena Rodríguez-Bocanegra ${ }^{2}$ \\ ${ }^{1}$ Grupo de Biotecnología Ambiental e Industrial (GBAI), Facultad de Ciencias, Pontificia Universidad Javeriana. Bogotá D.C., Colombia \\ ${ }^{2}$ Unidad de Investigaciones Agropecuarias (UNIDIA), Facultad de Ciencias, Pontificia Universidad Javeriana. Bogotá D.C., Colombia \\ ${ }^{3}$ Grupo de Enfermedades Infecciosas, Facultad de Ciencias, Pontificia Universidad Javeriana. Bogotá D.C., Colombia \\ *mxrodriguez@javeriana.edu.co
}

Recibido: 02-05-2011; Aceptado: 15-06-2011

\begin{abstract}
Resumen
Objetivo. Determinar actividades amilolíticas, celulolíticas, lipolíticas, pectinolíticas y proteolíticas en 32 aislamientos de Fusarium spp. de origen humano, animal y vegetal. Materiales y métodos. Las actividades enzimáticas se determinaron a nivel cualitativo, por medio de la medición de halos de hidrólisis en placas de agar con el respectivo sustrato, y a nivel cuantitativo se realizó un cultivo líquido para determinar la degradación del respectivo sustrato por medio de técnicas colorimétricas. Resultados. Todos los aislamientos presentaron actividades enzimáticas a nivel cualitativo, excepto las amilolíticas y lipolíticas. La determinación a nivel cuantitativo fue posible para las enzimas evaluadas, a excepción de las lipasas. Conclusión. La determinación de los perfiles enzimáticos amilolíticos, celulolíticos, pectinolíticos y proteolíticos de cada uno de los aislamientos evaluados pertenecientes al género Fusarium sugirió su capacidad, indistintamente de su procedencia, de degradar estos sustratos.
\end{abstract}

Palabras clave: Fusarium, patógeno multihospedero, amilasas, celulasas, pectinasas, proteasas, lipasas.

\begin{abstract}
Assessment of enzymatic characterization of Fusarium spp. isolated from human, animal, and plant wounds. Objective. To determine amylolytic, cellulolytic, lipolytic, pectinolytic and proteolytic activities in 32 Fusarium spp. isolates from humans, animals and plants. Materials and methods. Qualitative determination of enzymatic activities was done by measuring hydrolysis halos in agar plates with their corresponding substrate. Quantitative determination was done by colorimetric techniques, using liquid culture supernatants to determine the respective substrate degradation. Results. All isolates showed enzymatic activities from a qualitative point of view, except amylolytic and lipolytic. Quantitative determination was possible for all the evaluated enzymes except lipases. Conclusion. The determination of amylolytic, cellulolytic, pectinolytic and proteolytic enzymatic profiles of each of the Fusarium isolates assessed suggests their capacity to degrade these substrates, irrespectively of their origin.
\end{abstract}

Key words: Fusarium, multihost pathogen, amylases, celluloses, pectinases, proteases, lipases

\section{Resumo}

Avaliação das atividades enzimáticas de Fusarium spp. Isolados a partir de lesões em humanos, animais e plantas. Objetivo. Determinar as atividades amilolíticas, celulolíticas, lipolítica, pectinolíticas e proteolíticas em 32 isolamentos de Fusarium spp. de origem humana, animal e vegetal. Materiais e métodos. As atividades enzimáticas foram determinadas a nível qualitativo medindo os halos de hidrólise em placas de agar com o substrato respectivo e a nível quantitativo realizou-se uma cultura líquida para determinar a degradação do substrato respectivos por meio de técnicas colorimétricas. Resultados. Todos os isolados apresentaram uma atividade enzimática a nível 
qualitativo, exceto as amilolíticas e lipolíticas. A determinação a nível quantitativo foi possível para as enzimas testadas, exceto para as lipases. Conclusão. A determinação de perfis enzimáticos amilolíticos, celulolíticos, pectinolíticos e proteolíticos de cada um dos isolados testados pertencentes ao gênero Fusarium, sugeriu sua capacidade, independentemente da sua origem, para degradar estes substratos.

Palavras-chave: Fusarium, patógeno multihospedeiro, amilases, celulases, pectinases, proteases, lipases.

\section{Introducción}

Los hongos son microorganismos patógenos oportunistas que causan enfermedad cuando las defensas de sus hospederos se encuentran débiles. Han desarrollado estilos de vida parasitarios asociados con la capacidad de reconocer y penetrar a un hospedero específico. Entre los principales hospederos se encuentran las plantas, seguidas por los mamíferos - incluido el hombre-, y por último los insectos (1). Para causar enfermedad los hongos patógenos tienen varios factores de virulencia, los cuales se despliegan determinando el potencial y la magnitud de la infección. Estos factores de virulencia le permiten al hongo adherirse, penetrar e interferir con las funciones celulares de su hospedero (1). Entre sus numerosos y variados factores de virulencia se destaca el papel de las enzimas, mecanismo de virulencia asociado directamente con hongos con capacidad multihospedero. Estas enzimas le permiten al hongo degradar constituyentes importantes de las barreras de protección externa de los hospederos, por lo cual puede penetrar y colonizar tejidos (2).

Recientemente el género Fusarium ha sido considerado como modelo de patogénesis multihospedero, por su capacidad de infectar tanto a plantas como a animales y humanos. En plantas es el agente causal del marchitamiento vascular, enfermedad que afecta a una gran variedad de cultivos de gran importancia económica en todo el mundo. El género Fusarium es conocido actualmente como un patógeno oportunista emergente en animales y humanos que produce enfermedades como la queratomicosis y la onicomisis, entre otras. También ha sido reportado como el segundo género más frecuente causante de infección fúngica invasiva en pacientes inmunocomprometidos $(1,3)$.

Por lo anterior, el objetivo de esta investigación consistió en determinar perfiles enzimáticos amilolíticos, celulolíticos, lipolíticos, pectinolíticos y proteolíticos en cada uno de los 32 aislamientos del género Fusarium evaluados, provenientes de procesos patogénicos en plantas, animales y humanos.

\section{Materiales y métodos}

\section{Microorganismos}

Los aislamientos pertenecientes al género Fusarium que se utilizaron en este estudio provienen de estudios anteriores, en los cuales se realizaron aislamientos del microorganismo a partir de lesiones de humanos, animales y plantas que fueron identificados a nivel de especie por caracterización morfológica y secuenciación de ADNr región ITS4-ITS5 y factor de elongación $1 \alpha$ (Tabla 1) (4). Estos aislamientos (cultivos monoconidiales), conservados en agua destilada estéril, los proporcionó la colección de microorganismos del Laboratorio de Micología de la Pontificia Universidad Javeriana. La recuperación de los aislamientos se llevó a cabo a partir de cuadros de agar-micelio sembrados en medio Agar Papa Dextrosa (PDA) e incubados a $30^{\circ} \mathrm{C}$ durante diez días.

\section{Reconstitución de los microorganismos}

A partir de los aislamientos en PDA se tomaron discos de $5 \mathrm{~mm}$ de diámetro de agar-micelio y se sembraron en cajas de petri con agar almidón, carboximetil celulosa, leche descremada y pectina cítrica, cuya composición fue igual en todos los casos (g/L): 10 del polímero, sulfato de amonio 0,5 , cloruro de calcio 0,5 , fosfato monobásico de potasio 0,1 , fosfato dibásico de potasio 0,1 y agar 15 . También se hizo siembra en agar yema de huevo $2 \%(\mathrm{v} / \mathrm{v})$ y otros compuestos $(\mathrm{g} / \mathrm{L})$ : extracto de levadura 2,5 , sulfato de amonio 0,5 , cloruro de calcio 0,5 , fosfato monobásico de potasio 0,1 , fosfato dibásico de potasio 0,1 y agar 15 . El pH de todos los medios se ajustó a 6,5. Los aislamientos se incubaron a $30^{\circ} \mathrm{C}$ durante ocho días.

\section{Pruebas de caracterización enzimática cualitativa}

A partir de los microorganismos reconstituidos se tomaron discos de agar-micelio y se sembraron en cajas de petri con agar almidón, carboximetil celulosa, leche, pectina cítrica y yema de huevo, respectivamente. Se incubaron durante cuatro días a una temperatura de $30^{\circ} \mathrm{C}$. Se hicieron lecturas en los días dos y cuatro, midiendo el tamaño de los halos de hidrólisis. Todas las pruebas se realizaron por triplicado.

\section{Actividad amilolítica}

La actividad amilolítica se determinó por la presencia de zonas de aclaramiento alrededor de las colonias, debido a la hidrólisis del almidón, revelado con lugol (5). 
Tabla 1. Aislamientos de Fusarium spp. codificados según su procedencia

\begin{tabular}{|c|c|c|c|c|}
\hline Origen & $\begin{array}{l}\text { Código } \\
\text { aislamiento }\end{array}$ & Identificación taxonómica & Hospedero & Lesión \\
\hline \multirow{10}{*}{ Animal } & 108 & F. solani & Bovino & Lagrimeo abundante e inflamación del párpado \\
\hline & 111 & F. equiseti & Canino & $\begin{array}{l}\text { Dermatitis generalizada en extremidades } \\
\text { anteriores }\end{array}$ \\
\hline & 121 & F. sporotrichioides & Canino & Dermatitis generalizada en lomo zona anterior \\
\hline & 131 & F. equiseti & Canino & Dermatitis generalizada en lomo zona anterior \\
\hline & 155 & F. verticillioides & Canino & Dermatitis en lomo zona posterior \\
\hline & 156 & F. verticillioides & Canino & Dermatitis en lomo zona posterior \\
\hline & 159 & F. sporotrichioides & Canino & Dermatitis generalizada en zona abdominal \\
\hline & 160 & F. sporotrichioides & Bovino & Dermatitis en lomo zona media \\
\hline & 161 & F. verticillioides & Canino & Dermatitis en lomo zona media \\
\hline & 162 & F. oxysporum & Canino & Dermatitis en lomo zona posterior \\
\hline \multirow[t]{10}{*}{ Humano } & 201 & F. sporotrichioides & Clínico & Onicomicosis \\
\hline & 202 & F. oxysporum & Clínico & Onicomicosis \\
\hline & 203 & F. verticillioides & Clínico & Queratitis \\
\hline & 204 & F. oxysporum & Clínico & Onicomicosis \\
\hline & 205 & F. oxysporum & Clínico & Onicomicosis \\
\hline & 206 & F. oxysporum & Clínico & Onicomicosis \\
\hline & 207 & F. oxysporum & Clínico & Onicomicosis \\
\hline & 208 & F. oxysporum & Clínico & Onicomicosis \\
\hline & 209 & F. oxysporum & Clínico & Onicomicosis \\
\hline & 210 & F. oxysporum & Clínico & Onicomicosis \\
\hline \multirow[t]{12}{*}{ Vegetal } & 302 & F. oxysporum & Clavel & $\begin{array}{l}\text { Marchitamiento unilateral de la planta y } \\
\text { pudrición de haces vasculares }\end{array}$ \\
\hline & 303 & F. oxysporum & Tomate & $\begin{array}{l}\text { Marchitamiento unilateral de la planta y } \\
\text { pudrición de haces vasculares }\end{array}$ \\
\hline & 305 & F. oxysporum & Tomate & $\begin{array}{l}\text { Marchitamiento generalizado y pudrición de } \\
\text { haces vasculares }\end{array}$ \\
\hline & 308 & F. oxysporum & Tomate & $\begin{array}{l}\text { Marchitamiento generalizado y pudrición de } \\
\text { haces vasculares }\end{array}$ \\
\hline & 309 & F. oxysporum & Tomate & $\begin{array}{l}\text { Marchitamiento generalizado y pudrición de } \\
\text { haces vasculares }\end{array}$ \\
\hline & 310 & F. oxysporum & Tomate & $\begin{array}{l}\text { Marchitamiento generalizado y pudrición de } \\
\text { haces vasculares }\end{array}$ \\
\hline & 311 & F. oxysporum & Tomate & $\begin{array}{l}\text { Marchitamiento generalizado y pudrición de } \\
\text { haces vasculares }\end{array}$ \\
\hline & 312 & F. oxysporum & Tomate & $\begin{array}{l}\text { Marchitamiento generalizado y pudrición de } \\
\text { haces vasculares }\end{array}$ \\
\hline & 313 & F. oxysporum & Clavel & $\begin{array}{l}\text { Marchitamiento unilateral de la planta y } \\
\text { pudrición de haces vasculares }\end{array}$ \\
\hline & 314 & F. oxysporum & Clavel & $\begin{array}{l}\text { Marchitamiento unilateral de la planta y } \\
\text { pudrición de haces vasculares }\end{array}$ \\
\hline & 315 & F. oxysporum & Clavel & $\begin{array}{l}\text { Marchitamiento unilateral de la planta y } \\
\text { pudrición de haces vasculares }\end{array}$ \\
\hline & 317 & F. oxysporum & Clavel & $\begin{array}{l}\text { Marchitamiento unilateral de la planta y } \\
\text { pudrición de haces vasculares }\end{array}$ \\
\hline
\end{tabular}




\section{Actividad celulolítica}

La actividad celulolítica se determinó por la presencia de zonas de aclaramiento, en razón de la hidrólisis de la celulosa, revelado con rojo congo (6).

\section{Actividad lipolítica}

La actividad lipolítica se determinó directamente por zonas de precipitación alrededor de las colonias (7).

\section{Actividad pectinolítica}

La actividad pectinolítica se determinó por la presencia de zonas de aclaramiento alrededor de las colonias, a causa de la hidrólisis de la pectina, revelado con lugol (5).

\section{Actividad proteolítica}

La actividad proteolítica se determinó directamente por la observación de zonas de aclaramiento alrededor de las colonias, debido a la hidrólisis de la caseína presente en la leche descremada (6).

\section{Pruebas de evaluación de actividad enzimática cuantitativa}

Con el fin de confirmar las actividades enzimáticas observadas en las pruebas cualitativas, se determinó la actividad enzimática cuantitativa para cada uno de los aislamientos. Todas las pruebas se realizaron por triplicado. Para lo anterior se tomaron tres discos de agar-micelio y se inocularon en frascos con capacidad de $120 \mathrm{~mL}$, que contenían $25 \mathrm{~mL}$ de caldo almidón, carboximetil celulosa, leche, pectina cítrica y yema de huevo, con la misma composición mencionada anteriormente, pero sin agar. Estos cultivos se llevaron a condiciones de agitación constante a 150 rpm durante cuatro días a $30^{\circ} \mathrm{C}$, para el caso de las actividades amilolíticas, celulolíticas y pectinolíticas, en las cuales se evaluó la actividad enzimática por degradación del sustrato a través del tiempo, cuantificada por medio de la cantidad de glucosa y ácido galacturónico liberada para los días dos y cuatro. En el caso de la actividad lipolítica y proteolítica se evaluó mediante la reacción del extracto crudo, con los respectivos sustratos durante $60 \mathrm{~min} \mathrm{a} 30^{\circ} \mathrm{C}$. Para la actividad lipolítica se evaluó el extracto obtenido después de ocho días de fermentación, debido a que en los días dos y cuatro no se obtuvieron resultados positivos, y para la actividad proteolítica se evaluó el extracto crudo obtenido después de dos días de fermentación.

\section{Determinación de la actividad amilolítica, celulolítica y pectinolítica}

La determinación de la actividad amilolítica, celulolítica y pectinolítica se llevó a cabo cuantificando los azúcares reductores presentes en el cultivo, por medio de la técnica del 3,5 ácido di-nitro-salicílico (DNS) (8). Las actividades enzimáticas se cuantificaron como la cantidad de glucosa o ácido galacturónico liberada en $\mathrm{g} / \mathrm{L}$. Para ello se realizaron curvas de calibración con glucosa y ácido galacturónico; así mismo, se expresaron como porcentaje de rendimiento neto de glucosa o ácido galacturónico (9). El rendimiento neto se calculó usando las siguientes ecuaciones:

$\%$ RNG $=\frac{\text { Concentración de Glucosa X } 162}{\text { Concentración de Almidón X } 180} \times 100$

$\% \mathrm{RNG}=\frac{\text { Concentración de Glucosa X } 162}{\text { Concentración de Celulosa X } 180} \times 100$

$\%$ RNAG $=\frac{\text { Concentración de Ácido Galacturónico X } 176}{\text { Concentración de Pectina X } 194} \times 100$ [3]

\section{Determinación de la actividad lipolítica}

Los cultivos se centrifugaron, luego de ocho días de incubación, a 2300 x g durante 15 min y se recuperó el sobrenadante (extracto crudo). En un tubo de ensayo se adicionaron $100 \mu \mathrm{l}$ del extracto crudo enzimático proveniente de cada uno de los aislamientos por evaluar y a continuación se adicionaron $900 \mu \mathrm{L}$ de p-nitrofenil-palmitato como sustrato, a una concentración de $3 \mathrm{mg} / \mathrm{ml}$ disuelto en acetona (10). Posteriormente se incubó a $30{ }^{\circ} \mathrm{C}$ durante $3 \mathrm{~h}$ y luego se leyó en espectrofotómetro a $450 \mathrm{~nm}$ (10-12). La actividad lipolítica se determinó con base en la cuantificación del p-nitrofenol liberado por la acción de las lipasas, teniendo en cuenta una curva de calibración con p-nitrofenol. Una unidad lipolítica (UL) se definió como la cantidad de enzima capaz de liberar $1 \mu \mathrm{mol}$ de p-nitrofenol por minuto bajo las condiciones de la prueba.

\section{Determinación de la actividad proteolítica}

Los cultivos se centrifugaron, luego de dos días de incubación, a 2300 x g durante quince minutos y se recuperó el sobrenadante (extracto crudo). En un tubo de ensayo se mezcló $1 \mathrm{~mL}$ del extracto crudo enzimático con $1 \mathrm{~mL}$ de solución de caseína $1 \%(\mathrm{p} / \mathrm{v})$ disuelta en buffer fosfato $0,1 \mathrm{M} \mathrm{pH} 7,0$. Se incubó a $30{ }^{\circ} \mathrm{C}$ durante $60 \mathrm{~min}$ y se adicionó $1 \mathrm{~mL}$ de ácido tricloro acético $15 \%(\mathrm{p} / \mathrm{v})$. Posteriormente se centrifugó a 2300 x g durante 5 minutos. El sobrenadante obtenido se leyó en espectrofotómetro a 280 $\mathrm{nm}$ (13). La actividad proteolítica se determinó con base en la cuantificación de tirosina liberada por la acción de las proteasas, teniendo en cuenta una curva de calibración con 
tirosina. Una unidad proteolítica (UP) se definió como la cantidad de enzima capaz de liberar $1 \mu \mathrm{mol}$ de tirosina por minuto bajo las condiciones de la prueba.

\section{Análisis estadístico}

Para este análisis se utilizaron medidas de tendencia central como el promedio y la desviación estándar. Teniendo en cuenta los resultados de las pruebas enzimáticas cualitativas y cuantitativas se realizó un análisis estadístico de varianza (ANOVA) con una prueba de comparaciones de medias de Tukey, con el fin de seleccionar los aislamientos que presentaron mayor actividad enzimática. Los resultados que presentaron homogeneidad de varianzas fueron analizados con la prueba no paramétrica de Kruskal Wallis, con una prueba de comparaciones de medias. En todos los análisis estadísticos se utilizaron los programas Statistix y Excel 2007 para Windows.

\section{Resultados}

Teniendo en cuenta que la información para los resultados es amplia, se mostrarán únicamente los datos de tres aislamientos de cada origen que obtuvieron los mejores resultados.

\section{Actividad amilolítica}

No fue posible determinar la actividad enzimática cualitativa por medio de la producción de halos de hidrólisis, ya que al realizar la lectura a los días dos y cuatro no se evidenciaron halos de hidrólisis alrededor de las colonias de ninguno de los 32 aislamientos evaluados. Los resultados de las pruebas cuantitativas demostraron la actividad amilolítica de los aislamientos por la cantidad de azúcares reductores liberados como maltosa o glucosa. En general, la actividad amilolítica fue mayor en el cuarto día del cultivo. Se destacan los rendimientos de los aislamientos provenientes de humanos (202, 205 y 208) y el 315 de origen vegetal (Figura 1).

\section{Actividad celulolítica}

Todos los aislamientos estudiados presentaron actividad celulolítica tanto a nivel cualitativo (Figura 2a) como a nivel cuantitativo (Figura 2b). Los porcentajes de rendimiento de glucosa fueron mayores en el cuarto día y se destacan los aislamientos 155, 206 y 305, con valores de 6,14\%; 4,27\% y $5,64 \%$, respectivamente. Los resultados son similares para los aislamientos de los tres orígenes.

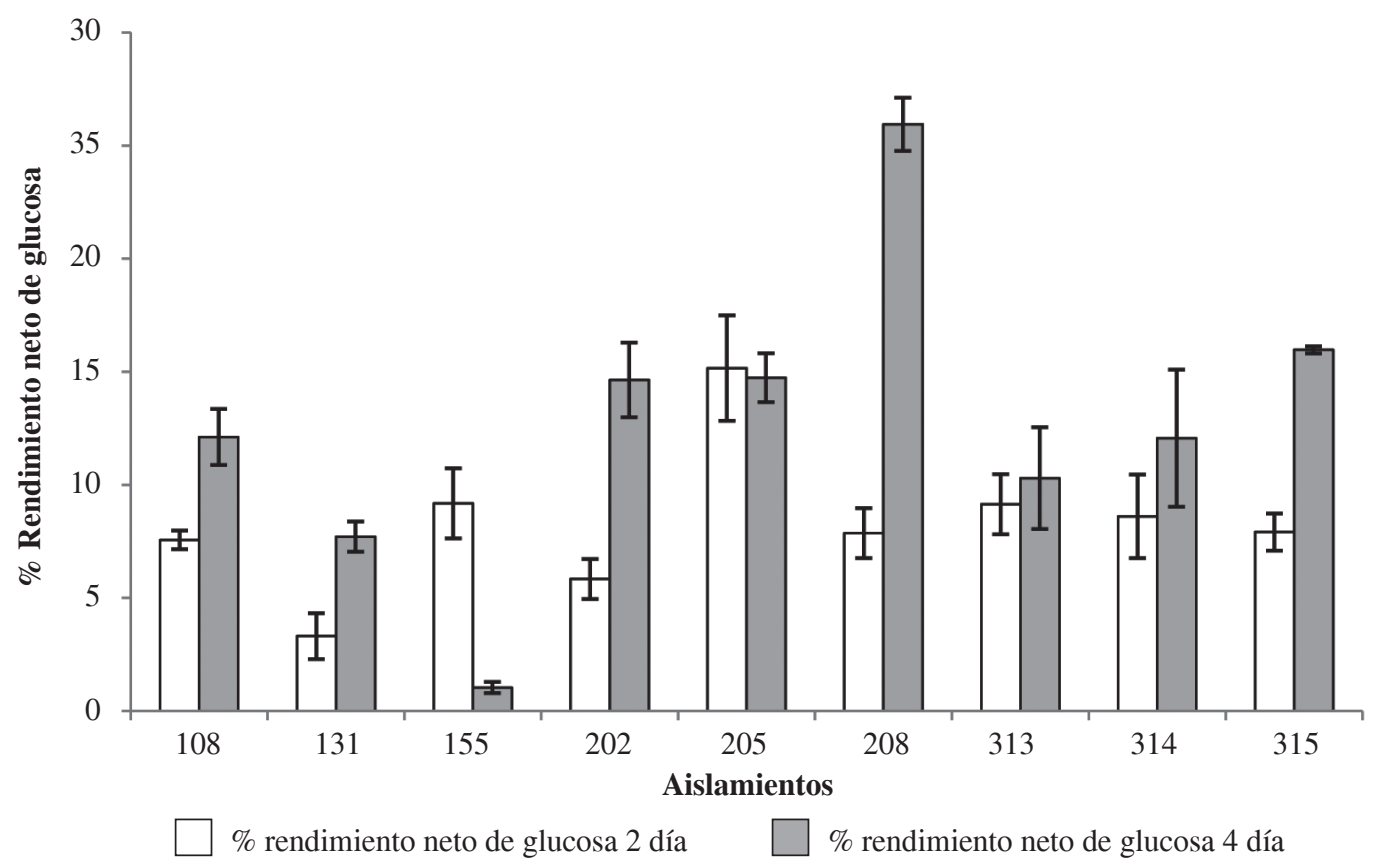

Figura 1. Actividad amilolítica cuantitativa de algunos aislamientos, expresada en porcentaje de rendimiento neto de glucosa en caldo almidón. Las barras de error corresponden a la desviación estándar. 


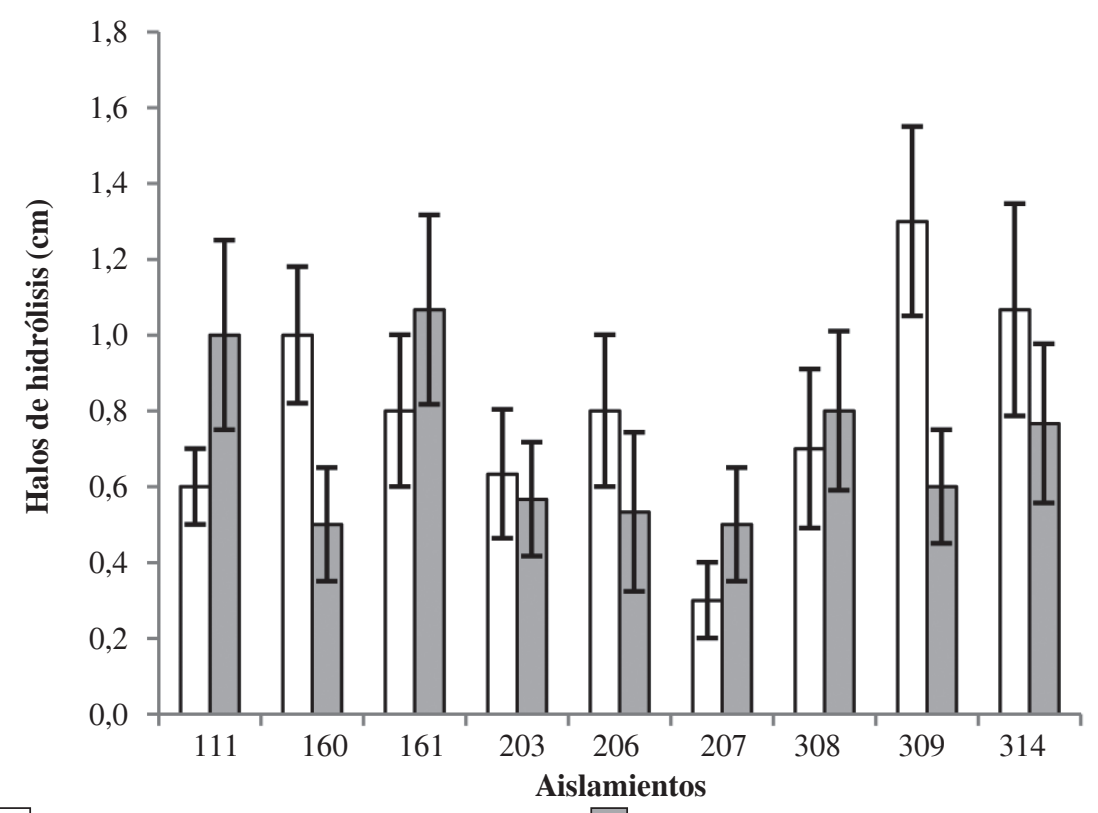

$\%$ rendimiento neto de glucosa 2 día $\quad \square \%$ rendimiento neto de glucosa 4 día

a

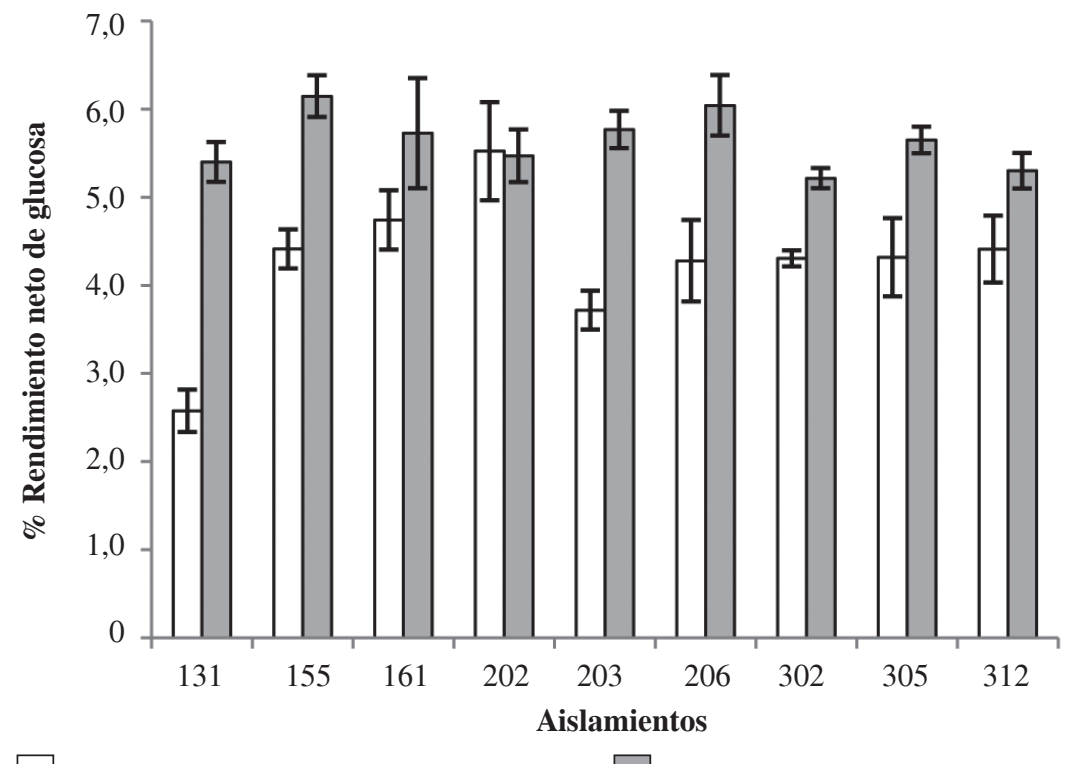

$\%$ rendimiento neto de glucosa 2 día

$\%$ rendimiento neto de glucosa 4 día

b

Figura 2. Actividad celulolítica de algunos aislamientos. (a) Actividad cualitativa expresada en halos de hidrólisis a través del tiempo de incubación en agar carboximetilcelulosa. (b) Actividad cuantitativa expresada en porcentaje de rendimiento neto de glucosa a través del tiempo de incubación en caldo carboximetilcelulosa. Las barras de error corresponden a la desviación estándar. 


\section{Actividad lipolítica}

No fue posible determinar la actividad enzimática cualitativa de todos los aislamientos evaluados por medio de la producción de halos de hidrólisis, cuando se usó como sustrato de inducción yema de huevo al $2 \%$, a pesar de que se realizaron lecturas en los días dos, cuatro, seis y diez. Aun así se observó que cada uno de los aislamientos evaluados presentó buen crecimiento durante el tiempo de incubación, mostrando todas las características macroscópicas comunes que identifican al género. Al no mostrar actividad lipolítica bajo estas condiciones, se evaluaron concentraciones de $1 \mathrm{y}$ $10 \%$ (v/v) de yema de huevo; sin embargo, no se evidenciaron halos de hidrólisis, pero sí crecimiento normal y rápido en cada uno de los aislamientos estudiados.

Adicionalmente, se evaluó si el uso de fuentes de nitrógeno orgánicas induciría la producción de enzimas lipolíticas, por lo que se adicionó al medio de cultivo peptona o extracto de levadura, o las dos fuentes a la vez, a una concentración de 2,5 g/L. Los resultados indicaron que el uso de peptona o extracto de levadura en el medio de cultivo sí inducía la producción de enzimas lipolíticas, pero los resultados fueron muy bajos y se dieron para el $21 \%$ de los aislamientos. Rapp en 1995 reportó que el uso de peptona como fuente de nitrógeno orgánica en el medio de cultivo incrementa la expresión de estas enzimas, deduciendo que estos sustratos tal vez contienen lípidos o aminoácidos capaces de inducir la formación de lipasas en Fusarium (14).

En cuanto a la prueba cuantitativa el resultado fue negativo ya que ningún aislamiento presentó actividad lipolítica bajo las condiciones de ensayo estudiadas.

\section{Actividad pectinolítica}

Todos los aislamientos presentaron actividad cualitativa. En la figura 3 (a) se muestran algunos ejemplos; se destaca el aislamiento 313 en el día dos (en el día cuatro no se observó halo de hidrólisis). Los ensayos a nivel cuantitativo son de gran importancia, como se ve en este aislamiento, el cual aunque presenta la mayor actividad cualitativa, no es el mejor a nivel cuantitativo, y el otro caso es el 314, que presentó un halo de hidrólisis mínimo, pero a nivel cuantitativo fue el mejor. A nivel cuantitativo todos los aislamientos de origen animal presentaron actividad, el $60 \%$ de los aislamientos de origen humano y el $70 \%$ de los aislamientos de origen vegetal. La mayoría de los aislamientos presentaron actividad pectinolítica cuantitativa en el día dos de lectura, aunque existieron valores muy bajos de porcentajes de rendimiento neto de ácido galacturónico. En la mayoría de los casos la actividad disminuyó en cuatro días (Figura 3b).

\section{Actividad proteolítica}

En general, a nivel cualitativo los halos de hidrólisis fueron muy bajos, en promedio $0,2 \mathrm{~cm}$, y algunos microorganismos no presentaron hidrólisis sino hasta el día seis (datos no mostrados). Los valores aumentaron para algunos aislamientos en el día cuatro, como es el caso de 203 y 314 (Figura 4a). A nivel cuantitativo, todos los aislamientos presentaron actividad proteolítica, pero el aislamiento 314, a pesar de ser el mejor a nivel cualitativo, no lo fue en las determinaciones a nivel cuantitativo. Los aislamientos que mostraron mayor actividad proteolítica cuantitativa fueron el 111, el 210 y el 310 en cada origen de aislamiento (Figura 4b).

\section{Análisis estadístico}

La prueba no paramétrica de Kruskal Wallis (95\%) no detectó diferencia estadística significativa comparando los días de evaluación de actividad enzimática $(\mathrm{P}>0,05)$, pero sí se presenta una diferencia numérica, lo que sugiere que la determinación enzimática realizada en el día dos o en el día cuatro de lectura es válida para considerar como positiva la actividad amilolítica, celulolítica, pectinolítica y proteolítica de los aislamientos evaluados. Esto indica que un tiempo de lectura es suficiente para determinar la actividad enzimática cualitativa de los aislamientos. La prueba de comparación de medias de Tukey (95\%) no detectó diferencia estadística ( $\mathrm{P}>0,05)$, pero sí numérica, en la determinación cuantitativa de la actividad amilolítica, celulolítica y pectinolítica de los aislamientos en los dos días de lectura. Esto sugiere que un tiempo de lectura es suficiente para determinar la actividad enzimática de los aislamientos, expresada en rendimiento neto de azúcares reductores. Por otra parte, se encontraron diferencias estadísticamente significativas $(\mathrm{p}<0,05)$ entre los tratamientos, es decir, entre los grupos de procedencia de los aislamientos.

\section{Discusión}

\section{Actividad amilolítica}

La no visualización de halos de hidrólisis en las pruebas cualitativas tal vez se deba al uso de agentes gelatinizantes como el agar-agar, el cual quizás actúa como inhibidor de las enzimas amilolíticas de los aislamientos evaluados (15). Además, durante las lecturas realizadas en los días dos y cuatro no se evidenció un crecimiento normal de los hongos en cuanto a velocidad radial de crecimiento (en promedio 1,4 $\mathrm{cm}$ de diámetro). Esto posiblemente sea consecuencia de que las enzimas amilolíticas no degradaran el sustrato presente, 


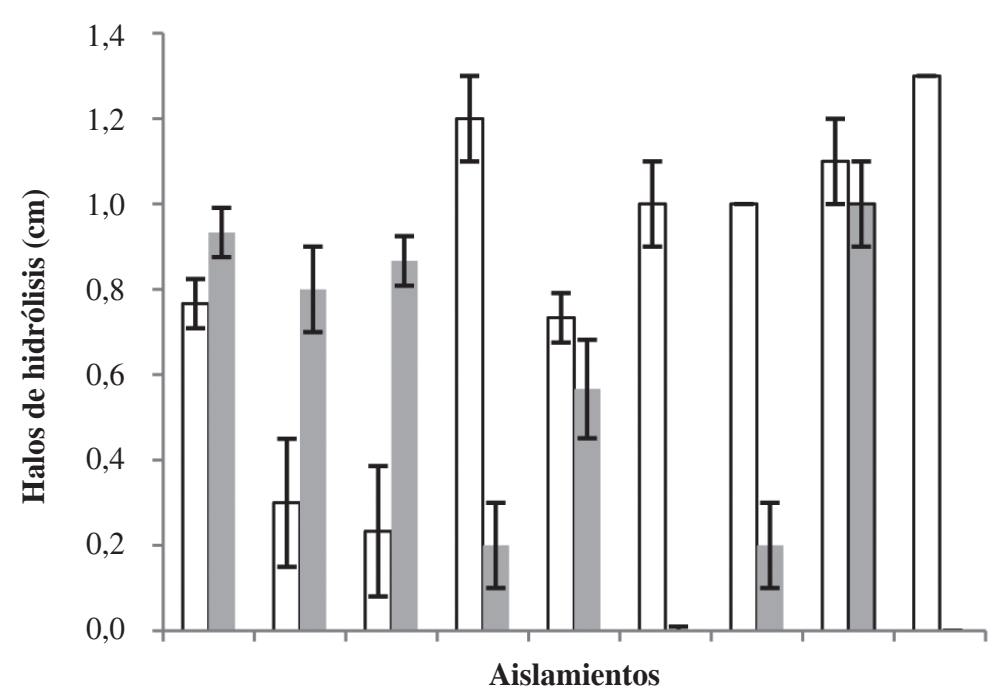

\% rendimiento neto de ácido galacturónico 2 día

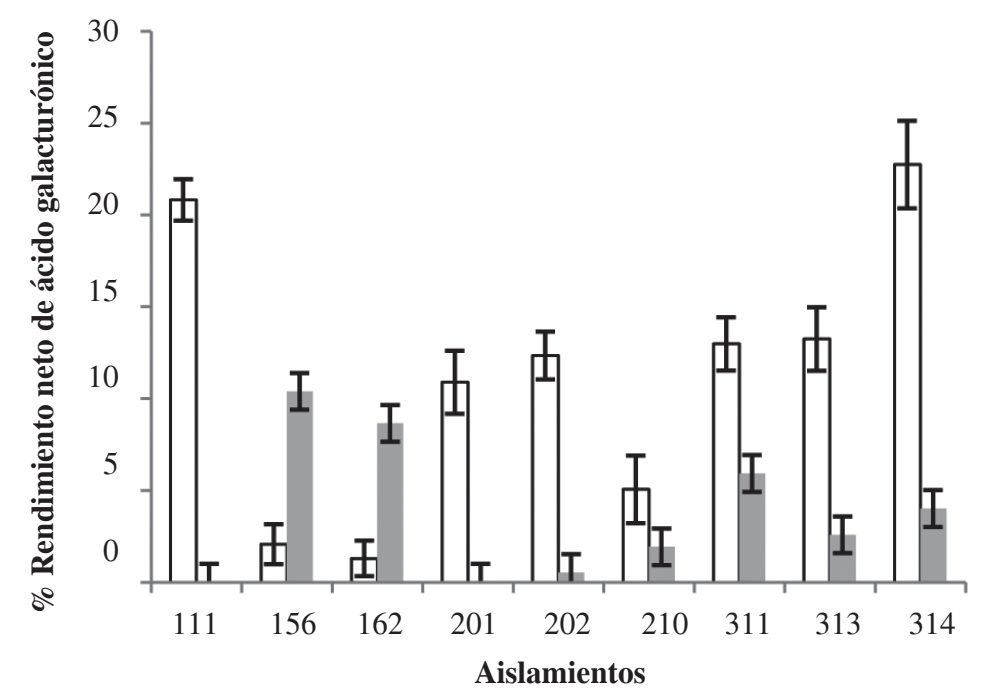

Figura 3. Actividad pectinolítica de algunos aislamientos. (a) Actividad cualitativa expresada en halos de hidrólisis a través del tiempo de incubación en agar pectina. (b) Actividad cuantitativa expresada en porcentaje de rendimiento neto de ácido galacturónico a través del tiempo de incubación en caldo pectina. Las barras de error corresponden a la desviación estándar. 


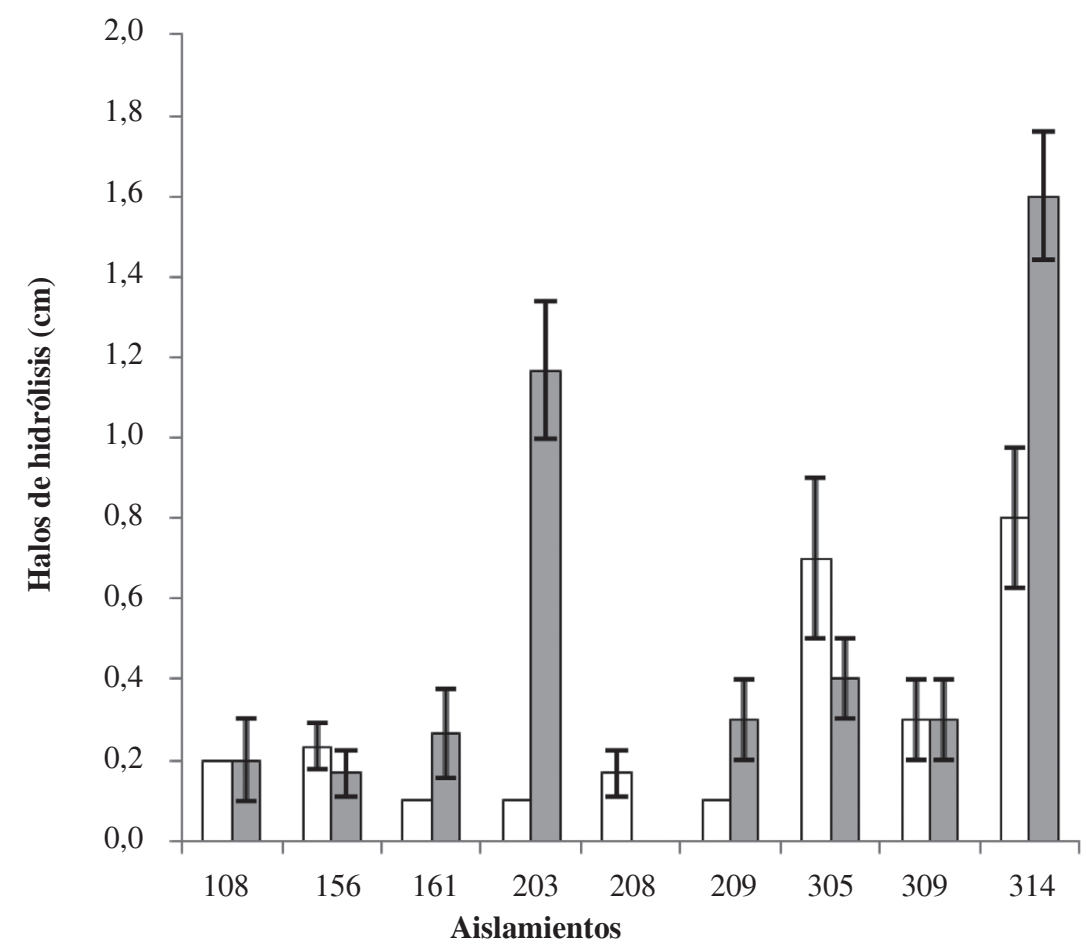

Halo de hidrólisis 2 día de lectura $\square$ Halo de hidrólisis 4 día de lectura

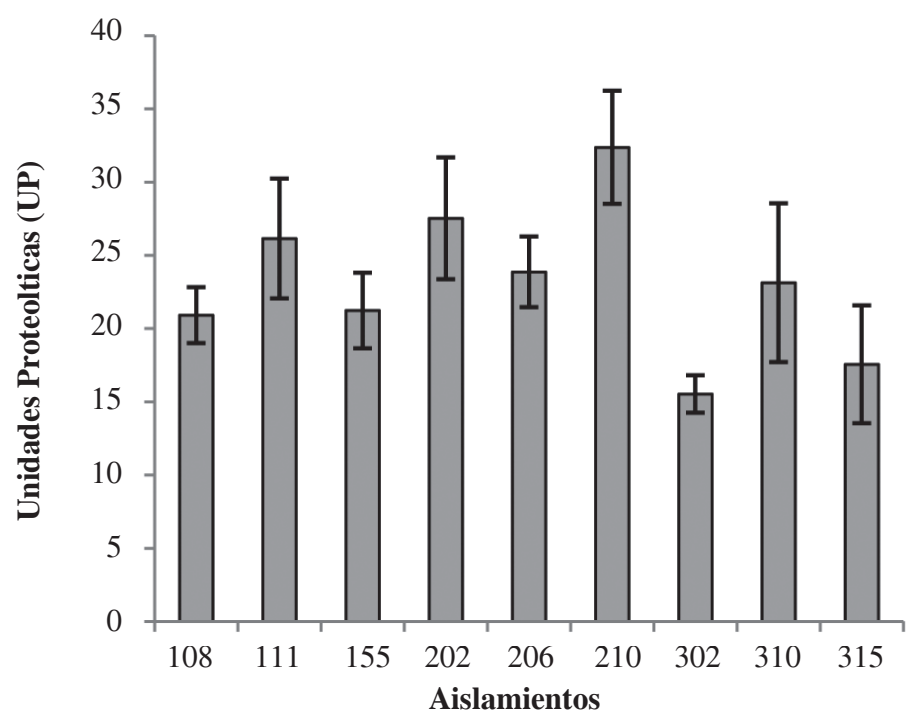

Unidades proteoliticas obtenidas por reacción enzimática

b

Figura 4. Actividad proteolítica de algunos aislamientos. (a) Actividad cualitativa expresada en halos de hidrólisis a través del tiempo de incubación en agar leche descremada. (b) Actividad cuantitativa expresada en $\mu$ moL de tirosina liberados por minuto por litro (UP). Las barras de error corresponden a la desviación estándar. 
ocasionando con ello la falta de liberación de glucosa, la cual no pudo ser usada por los hongos directamente y causó que este sustentara su crecimiento a partir de reservas energéticas. Por otra parte, Gupta et al., 2003, reportaron que las fuentes de nitrógeno orgánicas favorecen la producción de enzimas como las $\alpha$-amilasas (16). Ello resulta importante ya que la adición de fuentes de nitrógeno orgánicas fue un parámetro que no se tuvo en cuenta en la evaluación de esta actividad enzimática, con el fin de evitar que los microorganismos la usaran para sustentar su crecimiento y no producir enzimas.

Lo anterior sugiere que la utilización de un sustrato sólido para evidenciar la actividad enzimática y la falta de una fuente de nitrógeno orgánico pudieron ser factores limitantes para la expresión de las enzimas amilolíticas de los aislamientos provenientes del género Fusarium. $\mathrm{Al}$ realizar las pruebas cuantitativas en caldo almidón, se obtuvieron resultados que demostraron la expresión de enzimas amilolíticas (Figura 1), debido a la producción de azúcares reductores como maltosa o glucosa que surgen de la hidrólisis del enlace $\alpha$-1,4-glucosídico causado por las $\alpha$-amilasas o la acción hidrolítica de las $\beta$-amilasas o glucosidasas $(16,17)$.

La inducción de estas enzimas en caldo almidón, a pesar de usar fuente de nitrógeno inorgánico, se favoreció por la agitación, la cual permitió un mayor contacto entre el sustrato y la enzima y además mejor transferencia de oxígeno, lo cual pudo ocasionar un aumento de la producción enzimática (16). Así mismo, es preciso mencionar que el almidón no es un componente de la pared celular vegetal, sino que se encuentra como gránulos de reserva que viajan a través del sistema vascular y se localizan en raíces, bulbos y semillas. Por lo anterior esto podría ser una de las explicaciones de por qué este tipo de enzimas producidas por este género no se expresan en sustratos sólidos (18).

Los resultados obtenidos en las pruebas de actividad cuantitativa amilolítica sugirieron que los aislamientos provenientes de humanos, animales y plantas tienen capacidad enzimática para degradar un sustrato como el almidón. Para los fines de este estudio, los resultados obtenidos a partir de cada uno de los aislamientos provenientes de animales y humanos indican la posible capacidad de estos dos grupos de facilitar la colonización e invasión del patógeno dentro del tejido de las plantas y, lo que es aun más interesante, muestran que posiblemente, en un principio, la procedencia de estos aislamientos era de origen vegetal.

Por otra parte, las amilasas de este género no pertenecen al grupo de enzimas degradadoras de pared (CWDE's, Cell Wall Degrading Enzymes), por lo que la actividad amilolítica de este hongo no está asociada directamente con los mecanismos de penetración (1). La producción de amilasas está relacionada con la agresividad del patógeno, ya que le permiten asimilar componentes intracelulares como sustrato, pero no le dan la capacidad de degradar o penetrar la barrera estructural, que es la pared celular de las plantas (19); sin embargo, este tipo de constituyentes de la célula vegetal, como el almidón, las proteínas y las grasas, sólo pueden ser utilizados cuando han sido degradados por las enzimas secretadas por el patógeno (19).

\section{Actividad celulolítica}

El género Fusarium ha sido ampliamente reportado como un hongo con actividad enzimática celulolítica, condición que le permite establecerse en la superficie de la planta, constituida principalmente de celulosa, lo que produce ablandamiento, por la desintegración de los componentes de la pared celular, y permite la penetración y propagación del patógeno en los tejidos de su hospedero, lo que lleva al colapso y desintegración de su estructura celular (19).

En estudios anteriores $(19,20)$ se reporta el papel de las celulasas de Fusarium oxysporum f. sp. lycopersici en el marchitamiento vascular de la planta, debido a la liberación de grandes moléculas de celulosa dentro del xilema, lo cual interfiere el transporte normal de agua en estos haces vasculares. Además, las celulasas hacen parte de las enzimas degradadoras de paredes celulares (CWDE's) asociadas a la fitopatogenicidad de este género, las cuales son reguladas por inducción de sustrato y represión catabólica (21).

\section{Actividad lipolítica}

Para poder evidenciar la actividad lipolítica o fosfolipolítica de cada una de los aislamientos evaluados, se seleccionó yema de huevo como sustrato lipídico, debido a que esta tiene entre sus componentes lipídicos la lecitina que es un fosfolípido, cuyo nombre menos común es fosfatidilcolina, la cual es un elemento primordial de las bicapas lipídicas de las membranas celulares $(22,23)$. Por lo anterior, la utilización de la yema de huevo como sustrato permitiría relacionar de manera directa la acción degradativa e infectiva de los hongos evaluados sobre los tejidos epiteliales de animales o humanos. Tal acción estaría directamente relacionada con la posible desestabilización de membranas, lisis celular y liberación de lípidos que actúan como mensajeros secundarios. Además, existe evidencia substancial que indica el papel de las lipasas y fosfolipasas extracelulares como un factor de virulencia en infecciones por patógenos oportunistas como Cryptococcus y Candida $(24,25)$. Las pruebas de actividad enzimática cuantitativa no permitieron encontrar la actividad lipolítica de los aislamientos evaluados; aun así, no se puede desestimar que tanto el sustrato como el solvente empleados 
en la reacción enzimática pudieron, en cierta forma, inhibir la expresión de las posibles enzimas producidas por los aislamientos de Fusarium (26). Igualmente, no se podría concluir con base en los resultados que este tipo de enzimas no son expresadas por los hongos de este género, ya que diferentes autores han reportado la expresión de enzimas lipolíticas en el género Fusarium (14,27-29).

Christakopoulos et al., 1998, reportaron la producción de una esterasa por Fusarium oxysporum y encuentran que cuando se usa como sustrato p-nitrofenil-laurato y p-nitrofenil-palmitato, la actividad de la enzima es nula (30), lo que no ocurre cuando se usa p-nitrofenil-butirato y p-nitrofenil-acetato con mayor actividad para el p-nitrofenilbutirato. Este resultado sugiere que el uso de ésteres de cadena larga limita la actividad enzimática, o en su defecto la expresión de la enzima, y ello impide la determinación de enzimas lipolíticas $(11,30)$. Lo anterior pudo ocasionar la no determinación de lipasas en las pruebas de actividad enzimática, ya que se usó p-nitrofenil-palmitato (éster de cadena larga), como sustrato de reacción (31). Además, algunos estudios $(14,28)$ reportan que las lipasas producidas por hongos del género Fusarium son las enzimas que más necesitan ser inducidas por el uso de sustratos inductores como los aceites. A pesar de no haber tenido resultados positivos en este estudio, es importante continuar investigando, pues las lipasas extracelulares juegan un papel determinante como factor de virulencia en patógenos fúngicos (32).

\section{Actividad pectinolítica}

El género Fusarium ha sido reportado como un gran productor de enzimas pectinolíticas, Gómez et al., 2005, reportan la presencia de pectatoliasas y endopoligalacturonasas en Fusarium oxysporum f. sp. dianthi como causantes de marchitamiento vascular (33). Además, mencionan que estas enzimas pectinolíticas son las primeras enzimas producidas por los hongos fitopatógenos para romper y atacar los polímeros de la pared y la lámina media de la planta. La presencia de enzimas pectinolíticas en cada uno de los aislamientos de Fusarium spp. evaluados indica la capacidad de colonizar las plantas de las cuales son patógenos, penetrando a través de las raíces e invadiendo de esta manera su sistema vascular $(21,34,35)$.

\section{Actividad proteolítica}

Los resultados de las pruebas cualitativas realizadas sugirieron que todos los aislamientos tienen actividad proteolítica. Por otra parte, la rápida dispersión del micelio en las pruebas cualitativas sugiere que el sustrato proteico puede inducir la rápida propagación o proliferación del hongo y originar con ello que se den dermatomicosis, o lo que es mucho peor, una invasión infecciosa.

La determinación cuantitativa de la actividad proteolítica de los aislamientos sugiere que los aislamientos provenientes de animales, humanos y plantas tienen capacidad enzimática para degradar sustratos proteicos. Para los fines de este estudio, estos resultados son de gran relevancia ya que indican la posible capacidad de los aislamientos provenientes de lesiones de plantas para causar enfermedad en animales y humanos, pues la presencia de estas enzimas es uno de los factores enzimáticos necesarios para poder generar infección en estos hospederos. Adicionalmente, se confirma la capacidad de los aislamientos de degradar barreras constitutivas de su hospedero de origen, como son las extensinas (proteínas constitutivas de la pared celular de las plantas) (34-36). En cuanto a los aislamientos de animales y humanos, se indica la posible capacidad de estos dos grupos de causar infección cruzada en plantas. La actividad proteolítica de los aislamientos provenientes de lesiones dérmicas en animales y humanos indica la adaptación de su metabolismo a degradar sustratos proteicos queratináceos, los cuales integran la mayor parte del material contenido en las células que forman la epidermis de la piel de humanos, pelos, uñas, escamas, plumas, espinas, cuernos y pezuñas de animales (37).

Los resultados obtenidos de los perfiles enzimáticos amilolíticos, celulolíticos, pectinolíticos y proteolíticos, para cada uno de los aislamientos evaluados, indistintamente que provinieran de lesiones en humanos, animales y plantas, pueden ser correlacionados con la posible capacidad que tienen estos aislamientos de producir infección cruzada en diferentes hospederos. Lo anterior parte del hecho de que la capacidad enzimática amilolítica, celulolítica y pectinolítica está asociada directamente con hongos fitopatógenos. Para relacionar la actividad como patógeno oportunista en procesos de dermatomicosis se sugiere evaluar la actividad queratinolítica en sustratos de origen animal y humano. Adicionalmente, para confirmar la capacidad de Fusarium spp. como patógeno multihospedero, es necesario hacer pruebas de patogenicidad cruzada en hospederos vegetales (clavel y tomate) y animales (modelo murino).

\section{Conclusiones}

La determinación de los perfiles enzimáticos amilolíticos, celulolíticos, pectinolíticos y proteolíticos de cada uno de los aislamientos de Fusarium spp. de origen humano, animal y vegetal evaluados en este estudio, sugirió la capacidad de degradar barreras de protección y compuestos intracelulares de los diferentes hospederos, lo que se asocia con mecanismos de patogenicidad utilizados por hongos con capacidad multihospedero. 


\section{Financiación}

Este trabajo fue financiado por la Vicerrectoría Académica de la Pontificia Universidad Javeriana (Bogotá, D.C.), proyecto ID 002000.

\section{Conflicto de intereses}

Los autores declaran no tener conflicto de intereses con respecto a este estudio.

\section{Referencias}

1. Ortoneda M, Guarro J, Madrid MP, Caracuel Z, Roncero MI, Mayayo E, Di Pietro A. Fusarium oxysporum as a Multihost Model for the Genetic Dissection of Fungal Virulence in Plants and Mammals. Infection and Immunity. 2004; 72: 1760-66.

2. Echeverría A, Durante AG, Arechavala A, Negroni R. Estudio comparativo de dos medios de cultivo para la detección de la actividad fosfolipasa en aislamientos de Candida albicans y Cryptococcus neoformans. Revista Iberoamericana de Micología. 2002; 19: 95-98.

3. Bushelman SJ, Callen JP, Roth DN, Cohen LM. Disseminated Fusarium Solani Infection. Journal of the American Academy of Dermatology. 1995; 32: 346-51.

4. Vega, DR. Identificación y caracterización enzimática y molecular de aislamientos de Fusarium spp. de lesiones en animales, humanos y plantas [trabajo de grado de maestría]. Bogotá: Pontificia Universidad Javeriana, Facultad de Ciencias; 2010.

5. Marchi CE, Borges MD, Mizubuti ESG. Atividades amilolítica e pectinolítica de Alternaria solani e a relação com a agressividade em tomateiro. Summa Phytopathologica. 2006; 32 (4): 345-52.

6. Rojas JA, Cruz C, Mikán JF, Villalba LS, Cepero de García MC, Restrepo S. Isoenzyme Characterization of Proteases and Amylases and Partial Purification of Proteases from Filamentous Fungi Causing Biodeterioration of Industrial Paper. International Biodeterioration \& Biodegradation. 2009; 63: 169-75.

7. Fu Y, Ibrahim AS, Fonzi W, Zhou X, Ramos CF, Ghannoum MA. Cloning and Characterization of a Gene (LIP1) which Encodes a Lipase from the Pathogenic Yeast Candida albicans. Microbiology. 1997; 143: 331-40.

8. Miller GL. Use of Dinitrosalicylic Acid-Reagent for Determinations of Reducing Sugars. Analytical Chemistry. 1959; 31: 426-28.
9. Taniguchi M, Suzuki H, Watanabe D, Sakai K, Hoshino K, Tanaka T. Evaluation of Pretreatment with Pleurotus ostreatus for Enzymatic Hydrolysis of Rice Straw. Journal of Bioscience and Bioengineering. 2005; 100: 637-43.

10. Ateslier ZBB, Metin K. Production and Partial Characterization of a Novel Thermostable Esterase from Thermophilic Bacillus sp. Enzyme and Microbial Technology. 2006; 38: 628-35.

11. Gilham D, Lehner R. Techniques to Measure Lipase and Esterase Activity in Vitro. Methods. 2005; 36: 139-47.

12. Ertuqrul S, Dönmez G, Takaç S. Isolation of Lipase Producing Bacillus sp. from Olive Mill Wastewater and Improving its Enzyme Activity. Journal of Hazardous Materials. 2007; 149: 720-24.

13. Hübner U, Bock U, Schügerl K. Production of Alkaline Serine Protease Subtilis in Carlsberg by Bacillus licheniformis on Complex Medium in a Stirred Tank Reactor. Applied Microbiology and Biotechnology. 1993; 40: $182-88$.

14. Rapp P. Production, Regulation, and Some Properties of Lipase Activity from Fusarium oxysporum f. sp. vasinfectum. Enzyme and Microbial Technology. 1995; 17: 832-38.

15. Uhlig H. Industrial Enzymes and their Applications. Primera edición. John New York: Wiley \& Sons; 1998.

16. Gupta R, Gigras P, Mohapatra H, Goswami VK, Chauhan B. Microbial $\alpha$-amylases: a Biotechnological Perspective. Process Biochemistry. 2003; 38: 1599-1616.

17. Nigam P, Singh D. Enzyme and Microbial Systems Involved in Starch Processing. Enzyme and Microbial Technology. 1995; 17: 770-78.

18. Taiz L, Zieger E. Plant Physiology. Cuarta edición. Sunderland, Massachusetts, Estados Unidos: Sinauer Associates; 2006.

19. Agrios G. Plant Pathology. Quinta edición. Ámsterdam: Elsevier Academic Press; 2005.

20. Norkrans B. Degradation of Cellulose. Annual Reviews. 1963; 1: 323-50.

21. Roncero MI, Hera C, Ruiz-Rubio M, García F, Madrid M, Caracuel Z, Calero F, Delgado-Jarana J, RoldánRodríguez R, Martínez-Rocha AL, Velasco C, Roa J, Martín-Urdiroz M, Córdoba D, Di Pietro A. Fusarium as a Model for Studying Virulence in Soilborne Plant Pathogens. Physiological and Molecular Plant Pathology. 2003; 62: 87-98.

22. Wabel C. Influence of Lecithin on Structure and Stability of Parenteral Fat Emulsions [tesis doctoral]. Frankfurt, 
Alemania: Universidad de Erlangen-Nurnberg, Facultad de Ciencias Naturales; 1998.

23. Peña MT, Riesgo J. Nuevas funciones para las fosfolipasas y aciltransferasas de fosfolípidos: una breve revisión de las funciones y el metabolismo de fosfolípidos. Mensaje Bioquímico. 2005; 29: 65-80.

24. Cox GM, McDade HC, Chen SC, Tucker SC, Gottfredsson M, Wright LC, Sorrell TC, Leidich SD, Casadevall A, Ghannoum MA, Perfect JR. Extracellular Phospholipase Activity is a Virulence Factor for Cryptococcus neoformans. Molecular Microbiology. 2001; 39: 166-75.

25. Panizo M, Reviákina V, Flores Y, Montes W, González G. Actividad de fosfolipasas y proteasas en aislados clínicos de Candida spp. Revista de la Sociedad Venezolana de Microbiología. 2005; 25: 64-71.

26. Essamri M, Deyris V, Comeau L. Optimization of Lipase Production by Rhizopus oryzae and Study on the Stability of Lipase Activity in Organic Solvents. Journal of Biotechnology. 1998; 60: 97-103.

27. Mase T, Matsumiya Y, Akiba T. Purification and Characterization of a New Lipase from Fusarium sp. YM-30. Bioscience, Biotechnology and Biochemistry. 1995; 59: 1771-72.

28. Maia MMD, Heasley A, Camargo de Morais MM, Melo EHM, Morais MA, Ledingham WM, Lima JL. Effect of Culture Conditions on Lipase Production by Fusarium Solani in Batch Fermentation. Bioresource Technology. 2001; 76: 23-27.

29. Nagao T, Shimada Y, Sugihara A, Tominaga Y. Increase in Stability of Fusarium Heterosporum Lipase. Journal of Molecular Catalysis B: Enzymatic. 2002; 17: 125-32.
30. Christakopoulos P, Tzalas B, Mamma D, Stamatis H, Liadakis GN, Tzia C, Kekos D, Kolisis FN, Macris BJ. Production of an Esterase from Fusarium Oxysporum Catalyzing Transesterification Reactions in Organic Solvents. Process Biochemistry. 1998; 33: 729-33.

31. Gupta R, Gupta N, Rathi P. Bacterial Lipases: An Overview of Production, Purification and Biochemical Properties. Applied Microbiology and Biotechnology. 2004; 64: 763-81.

32. Stehr F, Kretschmar M, Kröger C, Hube B, Schäfer W. Microbial Lipases as Virulence Factors. Journal of Molecular Catalysis B: Enzymatic. 2003; 22: 347-55.

33. Gómez L, Martínez ST. Inducción de dos enzimas pectolíticas en el modelo Fusarium oxysporum f. sp. dianthi - Clavel. Revista Colombiana de Química. 2005; 34: 25-34.

34. Roncero MI, Di Pietro A, Ruiz-Roldán MC, Huertas MD, García-Maceira FI, Méglecz E, Jiménez A, Caracuel Z, Sancho R, Hera C, Gómez E, Ruiz M, González CI, Páez MJ. Papel de las enzimas líticas de la pared celular en la patogenicidad de Fusarium oxysporum. Revista Iberoamericana de Micología. 2000; 17: S47-S53.

35. Juge N. Plant Protein Inhibitors of Cell Wall Degrading Enzymes. Trends in Plant Science. 2006; 11: 359-67.

36. Pekkarinen A, Mannonen B, Jones BL, Niku-Paavola ML. Production of Proteases by Fusarium Species Grown on Barley Grains and in Media Containing Cereal Proteins. Journal of Cereal Science. 2000; 31: 253-61.

37. Mitola G, Escalona F, Ledesma A. Queratinolisis causada por hongos no dermatofitos aislados de una tenería y un matadero en Maracaibo-Venezuela: revisión de la expresión morfológica. Kasmera. 2001; 29: 1-21. 